\title{
Epidural analgesia in ICU chest trauma patients with fractured ribs: retrospective study of pain control and intubation requirements
}

Konstantinos Bachoumas ${ }^{1}$, Albrice Levrat ${ }^{2}$, Aurélie Le Thuaut ${ }^{3}$, Stéphane Rouleau ${ }^{4}$, Samuel Groyer ${ }^{5}$, Hervé Dupont ${ }^{6}$, Paul Rooze ${ }^{7}$, Nathanael Eisenmann ${ }^{8}$, Timothée Trampont ${ }^{9}$, Julien Bohé ${ }^{10}$, Benjamin Rieu ${ }^{11}$, Jean-Charles Chakarian ${ }^{12}$, Aurélie Godard ${ }^{13}$, Laura Frederici ${ }^{14}$, Stephanie Gélinotte ${ }^{15}$, Aurélie Joret ${ }^{16}$, Pascale Roques ${ }^{17}$, Benoit Painvin ${ }^{18}$, Christophe Leroy ${ }^{19}$, Marcel Benedit ${ }^{20}$, Loic Dopeux ${ }^{21}$, Edouard Soum ${ }^{22}$, Vlad Botoc ${ }^{23}$, Muriel Fartoukh ${ }^{24}$, Marie-Hélène Hausermann ${ }^{25}$, Toufik Kamel ${ }^{26}$, Jean Morin ${ }^{27}$, Roland De Varax ${ }^{28}$, Gaetan Plantefève ${ }^{29}$, Alexandre Herbland ${ }^{30}$, Matthieu Jabaudon ${ }^{31}$, Thibault Duburcq ${ }^{32}$, Christelle Simon ${ }^{33}$, Russell Chabanne ${ }^{34}$, Francis Schneider ${ }^{35}$, Frederique Ganster ${ }^{36}$, Cedric Bruel ${ }^{37}$, Ahmed-Saïd Laggoune ${ }^{38}$, Delphine Bregeaud ${ }^{39}$, Bertrand Souweine ${ }^{40}$, Jean Reignier ${ }^{41}$ and Jean-Baptiste Lascarrou ${ }^{41^{*}}$ (D)

\begin{abstract}
Background: Nonintubated chest trauma patients with fractured ribs admitted to the intensive care unit (ICU) are at risk for complications and may require invasive ventilation at some point. Effective pain control is essential. We assessed whether epidural analgesia (EA) in patients with fractured ribs who were not intubated at ICU admission decreased the need for invasive mechanical ventilation (IMV). We also looked for risk factors for IMV.

Study design and methods: This retrospective, observational, multicenter study conducted in 40 ICUs in France included consecutive patients with three or more fractured ribs who were not intubated at admission between July 2013 and July 2015.

Results: Of the 974 study patients, 788 were included in the analysis of intubation predictors. EA was used in 130 (16.5\%) patients, and 65 (8.2\%) patients required IMV. Factors independently associated with IMV were chronic respiratory disease $(P=0.008)$, worse SAPS II $(P<0.0001)$, flail chest $(P=0.02)$, worse Injury Severity Score $(P=0.0003)$, higher respiratory rate at admission $(P=0.02)$, alcohol withdrawal syndrome $(P<0.001)$, and noninvasive ventilation $(P=0.04)$. EA was not associated with decreases in IMV requirements, median numerical rating scale pain score, or intravenous morphine requirements from day 1 to day 7 .
\end{abstract}

Conclusions: EA was not associated with a lower risk of IMV in chest trauma patients with at least 3 fractured ribs, moderate pain, and no intubation on admission. Further studies are needed to clarify the optimal pain control strategy in chest trauma patients admitted to the ICU, notably those with severe pain or high opioid requirements.

Keywords: Epidural analgesia, Chest trauma

*Correspondence: jeanbaptiste.lascarrou@chu-nantes.fr

${ }^{41}$ Médecine Intensive Réanimation, University Hospital, Nantes, France

Full list of author information is available at the end of the article

\section{Take home points}

Study question: Does epidural analgesia improve pain control and/or decrease intubation requirements in patients with at least three fractured ribs who are not intubated at ICU admission? 
Results: The proportions of patients requiring intubation, pain scores, and intravenous analgesic needs were not significantly different in patients with vs. without epidural analgesia.

Interpretation: Epidural analgesia was not associated with a lower risk of invasive mechanical ventilation in chest trauma patients with at least 3 fractured ribs, moderate pain, and no intubation on admission.

\section{Introduction}

Fractured ribs are the most common chest injuries, being present in about $10 \%$ of trauma patients $[1,2]$. In the past, invasive mechanical ventilation (IMV) was the reference standard treatment for patients with multiple fractured ribs [3]. Whereas the need for IMV has decreased over time [4], mortality rates have remained remarkably stable in recent years $[4,5]$, with high mortality in patients with severe trauma [6], notably those who also have extrathoracic injuries [7]. These patients are usually intubated before intensive care unit (ICU) admission. Patients with fractured ribs who are not intubated at ICU admission may require IMV during their ICU stay and are at risk for several complications including pneumonia, atelectasis, and acute respiratory distress syndrome [8-11]. Older age, greater number of fractured ribs, concomitant injuries, and chronic lung disease are the main documented risk factors for complications $[12,13]$.

Achieving effective pain control is a key goal in the treatment of chest injuries [14]. Pain limits coughing efficiency and secretion clearance, thereby potentially leading to progressive atelectasis, loss of functional residual capacity (FRC) and, ultimately, respiratory distress. Pain control can improve ventilatory function and prevent respiratory complications [15]. Multiple modalities are available for alleviating pain due to chest injuries. Guidelines recommend epidural analgesia over nonregional modalities of pain control, but rest on a very low level of evidence $[16,17]$. No randomized controlled trial (RCT) has evaluated whether EA decreases the need for IMV in patients with chest injuries. A recent meta-analysis concluded that EA was not associated with a shorter IMV duration [18], whereas an analysis of a large dataset showed an association between EA and reduced mortality [19]. In addition, EA is performed only in 10-15\% of patients with fractured ribs [20], due to the existence in some patients of contraindications and to the need for specially trained staff to ensure safe catheter insertion and analgesic administration. We hypothesized that recent improvements in EA modalities might translate into better pain control with fewer technical obstacles, leading to an improvement in respiratory function with decreased IMV needs.
The primary aim of this retrospective study was to assess whether EA decreased IMV needs in chest trauma patients with fractured ribs who were not intubated at ICU admission. We also looked for factors predicting a need for IMV, under the hypothesis that knowledge of such factors might, in the future, improve the identification of those patients likely to benefit from EA.

\section{Methods}

\section{Study design and patients}

We conducted a retrospective, observational, multicenter study in 40 ICUs in France affiliated to 24 regional hospitals and 10 teaching hospitals.

The inclusion criteria were three or more posttraumatic fractured ribs [21], age $>18$ years, ICU admission between July 2013 and July 2015, and spontaneous breathing at ICU admission (including non-invasive ventilation). Noninclusion criteria were IMV started before ICU admission and previous ICU stays during the same hospital stay.

Eligible patients were identified by searching the electronic databases of each participating hospital using the International Classification of Diseases, 10th revision codes S22.4 for multiple fractured ribs, S22.5 for flail chest, and S27.1 for traumatic hemothorax. All patients with these codes were screened, and those meeting all the inclusion criteria and none of the noninclusion criteria were enrolled in the study.

\section{Definitions}

Flail chest was defined as fractures of three or more consecutive ribs in two or more places resulting in paradoxical chest wall motion during breathing [21]. Pneumonia was defined as early-onset pneumonia if onset occurred within $48 \mathrm{~h}$ after ICU admission and as nosocomial pneumonia if onset occurred later during the ICU stay. Patients were considered as having alcohol withdrawal syndrome if this diagnosis was recorded in the medical file by the physician in charge of the patient, before intubation if IMV was eventually required [22]. The numerical rating scale (NRS) scores for pain were recorded; on this scale, 0 indicates no pain and 10 the worst possible pain. Contraindications of EA were coagulation disorders (platelets $<50,000 / \mathrm{mm}^{3}$, prothrombin time $<50 \%$ ); treatment with ticlopidine, clopidogrel, prasugrel, ticagrelor, or one of the new anticoagulants; unstable spinal fracture; impaired consciousness or agitation; acute respiratory failure requiring immediate IMV; and shock requiring vasoactive drug administration [23].

\section{Data collection}

At each ICU, a local investigator abstracted the following data from the paper and/or electronic files of each 
patient: age, sex, Knaus and McCabe scores, and comorbidities (respiratory disease, smoking, alcohol abuse, obesity defined as a body mass index $>30$ ); respiratory rate, oxygen saturation, oxygen flow at ICU admission (first values in the patient file), and $\mathrm{PaO}_{2} / \mathrm{FiO}_{2}$ ratio calculated from $\mathrm{SpO}_{2} / \mathrm{FiO}_{2}$ using the formula from Rice et al. [24], with $\mathrm{FiO}_{2}$ estimated according to Coudroy et al. [25]; times from trauma to emergency department arrival and to ICU admission; number of fractured ribs; and presence of flail chest. The initial computed tomography (CT) scan was reviewed and the Injury Severity Score (ISS) and Abbreviated Injury Scale (AIS) score for each body region were determined by the same principal investigator to ensure reliability. The 2008 update of the 2005 AIS was used [26]. The following data from the ICU stay were also collected: Simplified Acute Physiology Score II (SAPS II) [27]; chest tube insertion during the ICU stay; NRS scores during the first 7 days; intravenous morphine consumption during the first $24 \mathrm{~h}(\mathrm{mg})$; need for intravenous morphine during the first 7 days (if other step- 3 analgesics were used intravenously, their doses were converted to morphine equivalents); use of other analgesics including nonsteroidal antiinflammatory drugs (NSAIDs), ketamine, tramadol, paracetamol, and nefopam; use of EA (the criteria for using EA were at the discretion of the physician in charge and were not recorded in the case report form); times from hospital and ICU admissions to EA; EA duration (days); EA modalities; complications of EA (epidural hematoma, epidural abscess, severe hypotension); contraindications of EA; patient refusal of EA; use of intercostal analgesia, with the time and duration if used; use of IMV with the reasons for IMV (respiratory, circulatory, and/or neurological failure; need for emergent surgery); time of intubation and duration of IMV; use of bilevel noninvasive ventilation (NIV) (before intubation if IMV was needed), with the reason (hypercapnic or pure hypoxic respiratory failure) and duration of NIV; surgical rib stabilization occurrence of alcohol withdrawal syndrome (before intubation if IMV was needed); occurrence of early-onset or nosocomial pneumonia; occurrence of ventilator-associated pneumonia (VAP); ICU and hospital stay lengths; and ICU and hospital mortality.

\section{Statistical analysis}

Qualitative data are described as counts and percentages and quantitative data as mean \pm SD if normally distributed and as median [IQR] otherwise. We checked the linearity of quantitative variables using the Shapiro-Wilk test. Nonlinear continuous variables were dichotomized based on their median.

We confined the analysis to patients without emergent surgery, contraindications of EA, failure to insert the epidural catheter, and refusal to receive EA. Univariate analyses were performed to identify factors associated with IMV. The Fine-Gray competing risks regression model was used to estimate subdistribution hazard ratios with their 95\% confidence intervals (95\% CIs). A multivariate model for predicting the need for IMV was then constructed using the variables associated with IMV at $P$ values $\leq 0.2$ by univariate analysis. Backward selection was applied until all remaining variables met the 0.05 threshold in the multivariate model. Only patients with no missing data were included in the multivariate analysis. Finally, we repeated the multivariate analysis in patients from ICUs where EA was used in at least 1 study patient and in patients whose NRS pain score was $>3$ on day 1.

All analyses were two-sided, and $P$ values $<0.05$ were considered significant. SAS software (v. 9.4 for Windows; SAS Institute) was used for the statistical analyses.

\section{Results}

Patient features at ICU admission and outcomes (Table 1 and Additional file 1: Figure S1)

We included 974 patients from 40 ICUs. Table 1 reports their main features and outcomes. IMV was required in 128 (13.1\%) patients.

\section{Pain management and use of epidural analgesia (EA) (Table 2, Additional file 1: Figure S1 and Additional file 2: Figure S2)}

EA was used in 130/788 (16.5\%) patients (Table 2). Of the 974 patients included, 21 required emergent surgery, 153 had contraindications, 4 refused EA, 6 had failed catheter insertion, and 2 had no data on EA use (Additional file 1: Figure S1). The proportion of patients who received EA varied widely across study ICUs, from 0 to $62 \%$ (Additional file 2: Figure S2). The only complication was severe hypotension with cardiac arrest in 1 patient. EA had no pain-relieving effect in $5(4 \%)$ patients.

Compared to the group without EA, the group with EA had higher mean values for the ISS and thoracic AIS score, a larger number of fractured ribs, a higher proportion of patients with flail chest, and greater oxygen needs at ICU admission. However, the EA group was similar to the non-EA group regarding the median NRS pain score and need for intravenous morphine during the first 7 ICU days. Also, the need for IMV was not significantly different between the two groups. The time from ICU admission to IMV initiation was not significantly shorter in the group without EA. NIV use was significantly more common in the EA group, which had longer median ICU and hospital stays compared to the non-EA group. 
Table 1 Baseline characteristics and outcomes

\begin{tabular}{|c|c|c|}
\hline & 974 patients & Missing data \\
\hline \multicolumn{3}{|l|}{ Demographic variables at baseline } \\
\hline Age, years, mean $\pm S D$ & $57 \pm 17$ & 10 \\
\hline Males, $n(\%)$ & $744 / 971(76.6 \%)$ & 3 \\
\hline \multicolumn{3}{|l|}{ Comorbidities, $n(\%)$} \\
\hline McCabe score & & 57 \\
\hline (0) No fatal underlying disease & $812 / 917(88.5 \%)$ & \\
\hline (1) Death expected within 5 years & 96/917 (10.5\%) & \\
\hline (2) Death expected within 1 year & 9/917 (1\%) & \\
\hline History of respiratory disease & 130/969 (13.4\%) & 5 \\
\hline COPD & $68 / 119(57 \%)$ & 11 \\
\hline Obstructive sleep apnea & $31 / 108(28.7 \%)$ & 22 \\
\hline Asthma & 25/111 (22.5\%) & 19 \\
\hline Pulmonary fibrosis & $6 / 105(5.7 \%)$ & 25 \\
\hline Lung cancer & $2 / 108(1.8 \%)$ & 22 \\
\hline Other & $16 / 109$ (14.6\%) & 21 \\
\hline History of alcohol abuse & $173 / 948(18.2 \%)$ & 26 \\
\hline History of smoking & $342 / 930(36.7 \%)$ & 44 \\
\hline Obesity (BMI $\geq 30)$ & $132 / 956(13.8 \%)$ & 18 \\
\hline \multicolumn{3}{|l|}{ Characteristics of the injury } \\
\hline Number of fractured ribs, mean $\pm S D$ & $6 \pm 3$ & 7 \\
\hline Flail chest, $n(\%)$ & 245/957 (25.6\%) & 17 \\
\hline Isolated chest trauma, $n(\%)$ & 276/971 (28.4\%) & 3 \\
\hline $\mathrm{PaO}_{2} / \mathrm{FiO}_{2}$ ratio at ICU admission ${ }^{\mathrm{a}}$ & 320 [254-390] & 25 \\
\hline SAPS II, mean \pm SD & $22 \pm 11$ & 26 \\
\hline Injury Severity Score, mean \pm SD & $18 \pm 7$ & 0 \\
\hline Thoracic AIS $\geq 3, n(\%)$ & $928(5.3 \%)$ & 0 \\
\hline Head AIS $\geq 3, n(\%)$ & $82(8.5 \%)$ & 6 \\
\hline Abdominal AIS $\geq 3, n(\%)$ & $97(10.0 \%)$ & 7 \\
\hline Face $\mathrm{AIS} \geq 3, n(\%)$ & $1(0.10 \%)$ & 9 \\
\hline Extremity AIS $\geq 3, n(\%)$ & $82(8.66 \%)$ & 4 \\
\hline External AIS $\geq 3, n(\%)$ & $0(0 \%)$ & 12 \\
\hline Time from injury to hospital admission, days, median [IQR] & $0[0-0]$ & 3 \\
\hline Time from injury to ICU admission, days, median [IQR] & $0[0-1]$ & 7 \\
\hline \multicolumn{3}{|l|}{ Outcome } \\
\hline$I M V, n(\%)$ & $128 / 974(13.1 \%)$ & \\
\hline Time from hospital admission to IMV, days, median [IQR] & $2[1-4]$ & 1 \\
\hline \multicolumn{3}{|l|}{ Reason for IMV (some patients had more than one reason) } \\
\hline Acute respiratory failure & 99 & \\
\hline Acute circulatory failure & 10 & \\
\hline Acute neurologic disorder & 14 & \\
\hline Emergency surgery & 21 & \\
\hline Time from ICU admission to IMV, days, median [IQR] & $2[1-3]$ & 1 \\
\hline IMV duration, days, median [IQR] & $8[3-14]$ & 3 \\
\hline Bilevel NIV, $n(\%)$ & 268/961 (27.9\%) & 13 \\
\hline Reason for NIV & & 13 \\
\hline Hypercapnia & $82(32.1 \%)$ & \\
\hline Hypoxemia & $165(64.8 \%)$ & \\
\hline Prophylactic & $8(3.1 \%)$ & \\
\hline NIV duration, days, median [IQR] & $3[1-4]$ & \\
\hline
\end{tabular}


Table 1 (continued)

\begin{tabular}{|c|c|c|}
\hline & 974 patients & Missing data \\
\hline Chest tube insertion, $n(\%)$ & $429 / 948(45.2 \%)$ & 26 \\
\hline Hemothorax & $146 / 425(34 \%)$ & 4 \\
\hline Pneumothorax & $159 / 425(37 \%)$ & 4 \\
\hline Hemothorax and pneumothorax & $119 / 425(28 \%)$ & 4 \\
\hline Surgery & $1 / 425(0.2 \%)$ & 4 \\
\hline Surgical stabilization of ribs, $n(\%)$ & $44 / 962(4.5 \%)$ & 12 \\
\hline Alcohol withdrawal syndrome, $n(\%)$ & 46/956 (4.8\%) & 18 \\
\hline \multicolumn{3}{|l|}{ Infection, n (\%) } \\
\hline Early-onset pneumonia (within $48 \mathrm{~h}$ after ICU admission) & 89/954 (9.3\%) & 20 \\
\hline Nosocomial pneumonia (> $48 \mathrm{~h}$ after ICU admission) & $89 / 912(9.8 \%)^{b}$ & 26 \\
\hline ICU stay length, median [IQR] & $5[3-9]$ & 6 \\
\hline Length of hospital stay (median, IQR) & $11[7-18]$ & 19 \\
\hline ICU mortality $(N, \%)$ & $31 / 965(3.2 \%)$ & 9 \\
\hline Hospital mortality ( $N$ \%) & $37 / 958(3.8 \%)$ & 16 \\
\hline
\end{tabular}

$M D$ missing data, COPD chronic obstructive pulmonary disease, $B M I$ body mass index, $I Q R$ interquartile range, IMV invasive mechanical ventilation, $A I S$ Abbreviated Injury Scale, SAPS II Simplified Acute Physiologic Score II, ICU intensive care unit, NIV noninvasive ventilation

a $\mathrm{PaO}_{2} / \mathrm{FiO}_{2}$ was not collected but was derived from $\mathrm{SpO}_{2}$ at ICU admission and the oxygen flow rate

b 36 patients died or were discharged within $48 \mathrm{~h}$ after ICU admission

\section{Risk factors for invasive mechanical ventilation (IMV)} (Additionnal file 3: Table S1 and Additionnal file 4: Table S2, Tables 3, 4)

IMV was required in $65(8.2 \%)$ patients. Table 3 reports the factors significantly associated with requiring IMV by univariate analysis. Figure 1 shows the cumulative incidence of IMV over time in the groups with and without EA.

Table 4 reports the results of the multivariate analysis in the 695 patients with no contraindications to, refusal of, or failure of catheter insertion for EA. Factors independently associated with requiring IMV were chronic respiratory disease, worse SAPS II, flail chest, worse ISS, higher respiratory rate at ICU admission, alcohol withdrawal syndrome, and prior use of NIV. EA was not independently associated with a decreased need for IMV.

The Additional file 3: Table S1 and Additional file 4: Table S2 show the results of the sensitivity analyses restricted to ICUs where at least 1 patient received EA and to patients whose NRS pain score was $>3$ on day 1 , respectively. In neither sensitivity analysis was EA associated with a decreased need for IMV (Additional file 3: Table S1 and Additional file 4: Table S2).

\section{Discussion}

In our large retrospective multicenter cohort study of chest trauma patients, EA was not associated with decreased IMV use. Factors independently associated with IMV were chronic respiratory disease, worse SAPS
II, flail chest, worse ISS, higher respiratory rate at ICU admission, and chronic alcohol abuse with alcohol withdrawal syndrome.

Pain control is a crucial component of the treatment strategy for patients with fractured ribs. Multiple fractured ribs cause severe pain that adversely affects the ability to cough and breathe deeply, thereby increasing the risk of secretion build-up and respiratory failure. In adults with blunt chest trauma, EA is recommended over nonregional pain-control modalities (i.e., intravenous or enteral analgesics such as opioids, acetaminophen, and NSAIDs) [16]. However, this recommendation is based on low-quality evidence, explaining perhaps in part the low compliance rates of $10 \%$ to $18 \%$ in several studies [20, $28,29]$. Similarly, in our study, EA was administered to only $16.5 \%$ of patients, and this proportion varied widely, from 0 to $62 \%$, across study ICUs. In 658 patients, no reason for not performing EA was recorded in the file. The disadvantages of EA may explain the low utilization rate. Catheter insertion may be technically demanding, and contraindications may be present in vulnerable patients admitted to the ICU. In our study, the physician in charge determined that EA was contraindicated in 153 (16\%) patients, and catheter insertion failed in $6(1 \%)$ additional patients. Complications of EA include hypotension, epidural hematoma [30], epidural infection [31], nausea, vomiting, pruritus, respiratory depression, and urinary retention [14]. EA can increase venous pooling, thereby increasing the risk of deep vein thrombosis [32]. However, serious complications are rare [33]. In our study, 
Table 2 Pain management and use of epidural analgesia

\begin{tabular}{|c|c|c|c|}
\hline & $\begin{array}{l}\text { No epidural analgesia } \\
(N=658)\end{array}$ & $\begin{array}{l}\text { Epidural analgesia } \\
(N=130)\end{array}$ & $P$ value \\
\hline \multicolumn{4}{|l|}{ Baseline characteristics } \\
\hline Age, years, mean $\pm S D$ & $55 \pm 17^{\mathrm{a}}$ & $57 \pm 16^{b}$ & 0.15 \\
\hline History of chronic respiratory disease, $n(\%)$ & $83 / 653(12.7 \%)$ & $14 / 130(10.8 \%)$ & 0.54 \\
\hline History of alcoholism, $n$ (\%) & $105 / 640(16.4 \%)$ & 26/123 (21.1\%) & 0.20 \\
\hline History of smoking, $n$ (\%) & 227/633 (35.9\%) & $44 / 123(35.8 \%)$ & 0.98 \\
\hline Obesity (BMI $\geq 30), n(\%)$ & $83 / 648(12.8 \%)$ & 25/126 (19.8\%) & 0.04 \\
\hline Number of fractured ribs $\geq 6, n(\%)$ & $312 / 656(47.6 \%)$ & $87 / 129(67.4 \%)$ & $<0.0001$ \\
\hline Flail chest, $n(\%)$ & $143 / 648(22.1 \%)$ & $57 / 129(44.2 \%)$ & $<0.0001$ \\
\hline Thoracic AIS (mean \pm SD) & $3.46 \pm 0.61$ & $3.75 \pm 0.53$ & $<0.0001$ \\
\hline Injury Severity Score, mean \pm SD & $17.5 \pm 7.0$ & $20.2 \pm 7.0$ & 0.0001 \\
\hline SAPS II, mean \pm SD & $21 \pm 10^{c}$ & $21 \pm 9^{d}$ & 0.46 \\
\hline \multicolumn{4}{|l|}{ Clinical variables at ICU admission } \\
\hline Oxygen saturation, $\%$, mean $\pm S D$ & $96 \pm 5^{e}$ & $96 \pm 3^{f}$ & 0.81 \\
\hline Respiratory rate, breaths/min, mean $\pm S D$ & $20 \pm 5^{9}$ & $20 \pm 5^{h}$ & 0.87 \\
\hline Oxygen flow > $6 \mathrm{~L} / \mathrm{min}, n(\%)$ & $117 / 649(18.0 \%)$ & $37 / 127$ (29.1\%) & 0.004 \\
\hline \multicolumn{4}{|l|}{ History of alcoholism } \\
\hline No & $535^{i}$ & $97^{j}$ & 0.41 \\
\hline Yes, without symptoms of withdrawal & 80 & 19 & \\
\hline Yes, with symptoms of withdrawal & 25 & 7 & \\
\hline \multicolumn{4}{|l|}{ Outcomes } \\
\hline Median NRS pain score on day $1>4, n(\%)$ & 243/637 (38.1\%) & $60 / 125(48.0 \%)$ & 0.04 \\
\hline Maximum NRS pain score from day 1 to day 4, median [IQR] & $6[5.0-8.0]$ & $7[5.0-8.0]$ & 0.03 \\
\hline \multicolumn{4}{|l|}{ Median numerical rating scale pain score, median [IQR] } \\
\hline Day 1 & $3.0[1.0-5.0]^{k}$ & $3.5[1.0-5.0]^{\prime}$ & 0.23 \\
\hline Day 2 & $2.5[1.0-4.0]^{k}$ & $2.5[0.5-4.0]^{\prime}$ & 0.37 \\
\hline Day 3 & $2.0[0.0-4.0]^{k}$ & $2.0[0.0-3.0]^{1}$ & 0.49 \\
\hline Day 4 & $2.0[0.0-3.5]^{k}$ & $1.0[0.0-3.0]^{\prime}$ & 0.01 \\
\hline Day 5 & $2.0[0.0-3.5]^{k}$ & $1.0[0.0-3.0]^{\prime}$ & 0.09 \\
\hline Day 6 & $2.0[0.0-3.0]^{k}$ & $2.0[0.0-3.0]^{\prime}$ & 0.36 \\
\hline Day 7 & $1.5[0.0-3.0]^{k}$ & $2.0[0.0-3.5]^{\prime}$ & 0.64 \\
\hline \multicolumn{4}{|l|}{ Intravenous morphine } \\
\hline Day $1, n(\%)$ & $395 / 657(60.1 \%)$ & $76 / 130(58.5 \%)$ & 0.72 \\
\hline Dose during the first $24 \mathrm{~h}$ in the ICU, mg, median [IQR] & $5[0-16]^{\mathrm{m}}$ & $5.0[0.0-14]^{n}$ & 0.78 \\
\hline Day $7, n(\%)$ & $62 / 657(9.4 \%)$ & $27 / 130(20.8 \%)$ & 0.0002 \\
\hline \multicolumn{4}{|l|}{ Other analgesics during the first 7 ICU days, $n$ (\%) } \\
\hline NSAIDs & $186 / 629(29.6 \%)$ & $42 / 129(32.6 \%)$ & 0.50 \\
\hline Ketamine & $63 / 625(10.1 \%)$ & $18 / 127(14.2 \%)$ & 0.17 \\
\hline Nefopam & $478 / 639(74.8 \%)$ & $96 / 128(75.0 \%)$ & 0.96 \\
\hline Paracetamol & $625 / 654(95.6 \%)$ & $124 / 129(96.1 \%)$ & 0.78 \\
\hline Tramadol & $361 / 633(57.0 \%)$ & $69 / 129(53.5 \%)$ & 0.46 \\
\hline Intercostal anesthesia & $18 / 658(2.1 \%)$ & & \\
\hline Days with intercostal anesthesia, median [IQR] & $4[3-5.5]$ & & \\
\hline \multicolumn{4}{|l|}{ Epidural analgesia } \\
\hline Patients with EA, $n(\%)$ & & 130/788 (16.5\%) & \\
\hline Time from hospital admission to EA, days, median [IQR] & & $1[0-2]$ & \\
\hline Time from ICU admission to EA, days, median [IQR] & & $1[0-2]$ & \\
\hline EA duration, days, mean $\pm S D$ & & $4.1 \pm 2.2^{\circ}$ & \\
\hline \multicolumn{4}{|l|}{ Local anesthetics, $n(\%)$} \\
\hline Ropivacaine & & $118 / 124(95.2 \%)$ & \\
\hline
\end{tabular}


Table 2 (continued)

\begin{tabular}{|c|c|c|c|}
\hline & $\begin{array}{l}\text { No epidural analgesia } \\
(N=658)\end{array}$ & $\begin{array}{l}\text { Epidural analgesia } \\
(N=130)\end{array}$ & $P$ value \\
\hline Bupivacaine & & $0 / 124(0 \%)$ & \\
\hline Levobupivacaine & & $6 / 124(4.8 \%)$ & \\
\hline \multicolumn{4}{|l|}{ Local opioids, $n$ (\%) } \\
\hline Sufentanil & & $96 / 125(76.8 \%)$ & \\
\hline Morphine & & $7 / 125(5.6 \%)$ & \\
\hline None & & $22 / 125(17.6 \%)$ & \\
\hline \multicolumn{4}{|l|}{ Complications, $n(\%)$} \\
\hline Epidural hematoma & & 0 & \\
\hline Epidural abscess & & 0 & \\
\hline Severe hypotension & & 1 & \\
\hline No pain relief from EA, $n(\%)$ & & $5 / 111(4.5 \%)$ & \\
\hline \multicolumn{4}{|l|}{ Mechanical ventilation } \\
\hline IMV, $n(\%)$ & $53 / 658(8.0 \%)$ & $12 / 130(9.2 \%)$ & 0.65 \\
\hline Time from ICU admission to IMV, days, median [IQR] & $2[1-4]^{p}$ & $2.5[1.5-5]^{9}$ & 0.52 \\
\hline IMV duration, days, median [IQR] & $9.5[5-16]^{p}$ & $10[4.5-13]^{a}$ & 0.97 \\
\hline \multicolumn{4}{|c|}{ Reason of IMV initiation (more than one possible for each patient) } \\
\hline Acute respiratory failure & 51 & 10 & 0.15 \\
\hline Acute neurologic failure & 6 & 3 & 0.35 \\
\hline Acute circulatory failure & 3 & 1 & 0.57 \\
\hline Noninvasive ventilation, $n$ (\%) & $146 / 647(22.6 \%)$ & $58 / 129(45.0 \%)$ & $<0.0001$ \\
\hline ICU stay length, days, median [IQR] & $5[2-8]^{r}$ & $8[6-12]$ & $<0.0001$ \\
\hline Hospital stay length, days, median [IQR] & $10[6-17]^{\mathrm{s}}$ & $13[9-18]^{t}$ & 0.0002 \\
\hline ICU mortality, $n(\%)$ & $13 / 653(2.0 \%)$ & $5 / 129(3.9 \%)$ & 0.20 \\
\hline Hospital mortality, $n$ (\%) & $15 / 650(2.3 \%)$ & $5 / 127(3.9 \%)$ & 0.35 \\
\hline
\end{tabular}

Where the available number of patients with data is not specified, all patients in the group had available data

$B M I$ body mass index, NRS numerical rating scale, IQR interquartile range, AIS Abbreviated Injury Scale, ISS Injury Severity Score, SAPS II Simplified Acute Physiology Score version II, NSAIDs nonsteroidal anti-inflammatory drugs, EA epidural analgesia, IMV invasive mechanical ventilation

a Available for $652 / 658$ patients

b Available for $128 / 130$ patients

c Available for $646 / 658$ patients

d Available for $124 / 130$ patients

e Available for $650 / 658$ patients

f Available for $128 / 130$ patients

g Available for $635 / 658$ patients

h Available for $123 / 130$ patients

i Available for $622 / 658$ patients

j Available for $116 / 130$ patients

k Available on days 1 through 7 for $637,598,505,408,300,232$, and 170 patients, respectively

I Available on days 1 through 7 for 125, 123, 121, 116, 105, 96, and 71 patients, respectively

$\mathrm{m}$ Available for $642 / 658$ patients

n Available for $129 / 130$ patients

- Available for $129 / 130$ patients

p Available for $52 / 53$ patients

q Available for $12 / 12$ patients

$r$ Available for $654 / 658$ patients

$s$ Available for $650 / 658$ patients

t Available for $128 / 130$ patients 
Table 3 Characteristics and outcomes of patients with and without invasive mechanical ventilation (IMV); patients who received IMV for emergent surgery, with contraindication for EA, refused EA, failed catheter insertion, missing data about EA were excluded

\begin{tabular}{|c|c|c|c|c|}
\hline & IMV $(N=65)$ & No IMV $(N=723)$ & HR $(95 \% \mathrm{Cl})$ & $P$ value \\
\hline \multicolumn{5}{|l|}{ Patient characteristics } \\
\hline Age, years, mean $\pm S D$ & $62 \pm 15$ & $55 \pm 17$ & $1.02(1.01-1.04)$ & 0.020 \\
\hline Chronic respiratory disease, $n(\%)$ & $23 / 65(35.4 \%)$ & $74 / 718(10.3 \%)$ & $3.98(2.39-6.61)$ & $<0.001$ \\
\hline Obesity (BMI > 30), $n(\%)$ & 12/64 (18.7\%) & $96 / 710(13.5 \%)$ & $1.38(0.72-2.61)$ & 0.33 \\
\hline History of smoking, $n(\%)$ & $32 / 64(50.0 \%)$ & 239/692 (34.5\%) & $1.91(1.17-3.10)$ & 0.009 \\
\hline Alcohol, $n(\%)$ & & & & $<0.001^{*}$ \\
\hline No chronic alcoholism & $43 / 64(67.2 \%)$ & $589 / 699(84.3 \%)$ & 1 (reference) & \\
\hline Alcohol abuse without alcohol withdrawal syndrome & 10/64 (15.6\%) & $89 / 699(12.7 \%)$ & $1.64(0.83-3.27)$ & \\
\hline Alcohol abuse with alcohol withdrawal syndrome & 12/64 (17.2\%) & $21 / 699(3.0 \%)$ & $5.14(2.54-10.4)$ & \\
\hline \multicolumn{5}{|l|}{ Injury characteristics } \\
\hline Thoracic AIS, mean \pm SD & $3.8 \pm 0.6$ & $3.5 \pm 0.6$ & $2.02(1.18-3.47)$ & 0.01 \\
\hline ISS, mean $\pm S D$ & $21 \pm 8$ & $18 \pm 7$ & $1.05(1.01-1.08)$ & 0.006 \\
\hline Flail chest, $n(\%)$ & 28/65 (43.1\%) & $172 / 712(24.2 \%)$ & $2.01(1.24-3.28)$ & 0.005 \\
\hline$\geq 6$ fractured ribs, $n(\%)$ & $36 / 64(56.2 \%)$ & $363 / 721(50.3 \%)$ & $1.13(0.68-1.86)$ & 0.64 \\
\hline SAPS II, mean \pm SD & $30.6 \pm 14^{b}$ & $20 \pm 9^{c}$ & $1.08(1.06-1.09)$ & $<0.001$ \\
\hline \multicolumn{5}{|l|}{ Clinical variables } \\
\hline Oxygen saturation at ICU admission, $\%$, mean \pm SD & $95 \pm 4$ & $96 \pm 5^{d}$ & $0.98(0.96-1.00)$ & 0.03 \\
\hline Respiratory rate at ICU admission, breaths/min, mean \pm SD & $23.0 \pm 6.8^{e}$ & $20.4 \pm 5.5^{f}$ & $1.07(1.03-1.12)$ & 0.002 \\
\hline Oxygen flow $>6 \mathrm{~L} / \mathrm{min}$ at ICU admission, $n(\%)$ & 28/64 (43.7\%) & $126 / 712(17.7 \%)$ & $3.08(1.87-5.05)$ & $<0.001$ \\
\hline Median NRS pain score on day $1>4$ & $31 / 61(50.8 \%)$ & $272 / 701(38.8 \%)$ & $1.49(0.91-2.43)$ & 0.12 \\
\hline \multicolumn{5}{|l|}{ Treatment } \\
\hline Epidural analgesia, $n(\%)$ & $12 / 65(18.5 \%)$ & $118 / 723(16.3 \%)$ & $0.83(0.43-1.57)$ & 0.56 \\
\hline Noninvasive ventilation, $n$ (\%) & $36 / 64(56.2 \%)$ & $168 / 712(23.6 \%)$ & $3.05(1.88-4.97)$ & 0.005 \\
\hline
\end{tabular}

Where the available number of patients with data is not specified, all patients in the group had available data

BMI body mass index, AIS Abbreviated Injury Scale, ISS Injury Severity Score, SAPS II Simplified Acute Physiology Score version II, NRS numerical rating scale

a Available for $715 / 723$ patients

b Available for $63 / 65$ patients

c Available for $707 / 723$ patients

d Available for $713 / 723$ patients

e Available for $58 / 65$ patients

f Available for 700/723 patients

* Global value

no patient experienced epidural hematoma or infection, and a single patient had severe hypotension with cardiac arrest very shortly after catheter insertion. However, this last patient had respiratory failure and hypotension before EA initiation. Conceivably, the use of more peripheral regional anesthesia approaches might provide better pain control than EA. Examples include the posterior paramedian sub rhomboidal block [34] and the erector spinae plane block [35]. However, data on these two methods are still scarce.

Nevertheless, no RCT has assessed the efficacy of EA in reducing the need for IMV. In three observational studies, EA was associated with increased IMV requirements $[15,20,36]$. However, these studies also included patients who were intubated before hospital admission. EA decreased the number of ventilator days in two RCTs [21, 37], but the sample sizes were small and the studies were mostly conducted before the recent major advances in IMV use and in weaning off IMV. Pulmonary complications were assessed in a few studies but varied widely, perhaps in part due to the diversity of definitions used [21, 38]. In several studies, EA was associated with longer hospital stays, suggesting inappropriate use of this analgesic modality [39]. In three meta-analyses, EA did not significantly affect IMV duration or lengths of ICU or hospital stay [18, 33, 40]. In a database study, Malekpour et al. [19] used propensity score matching to compare EA to a paravertebral 
Table 4 Multivariate analysis to identify risk factors associated with invasive mechanical ventilation (IMV) in the 695 patients with no contraindications to, refusal of, or failure of catheter insertion for epidural analgesia

\begin{tabular}{llcc}
\hline & aHR & 95\% Cl & P value \\
\hline History of chronic respiratory disease & 2.38 & $1.25-4.52$ & 0.008 \\
SAPS II & 1.07 & $1.04-1.09$ & 0.0001 \\
Flail chest & 2.00 & $1.13-3.52$ & 0.02 \\
ISS & 1.08 & $1.04-1.12$ & 0.0001 \\
Respiratory rate, breaths/min & 1.06 & $1.01-1.12$ & 0.02 \\
Epidural analgesia & 0.52 & $0.25-1.08$ & 0.08 \\
Noninvasive ventilation & 1.84 & $1.02-3.33$ & 0.04 \\
Alcohol & & & $<0.0001^{*}$ \\
No alcohol abuse & & &. \\
Alcohol abuse without alcohol withdrawal syndrome & 2.82 & $1.38-5.77$ & $3.61-15.6$ \\
Alcohol abuse with alcohol withdrawal syndrome & 7.50 &
\end{tabular}

aHR adjusted hazard ratio, 95\% CI 95\% confidence interval, SAPS II Simplified Acute Physiology Score version II, ISS Injury Severity Score

* Global value

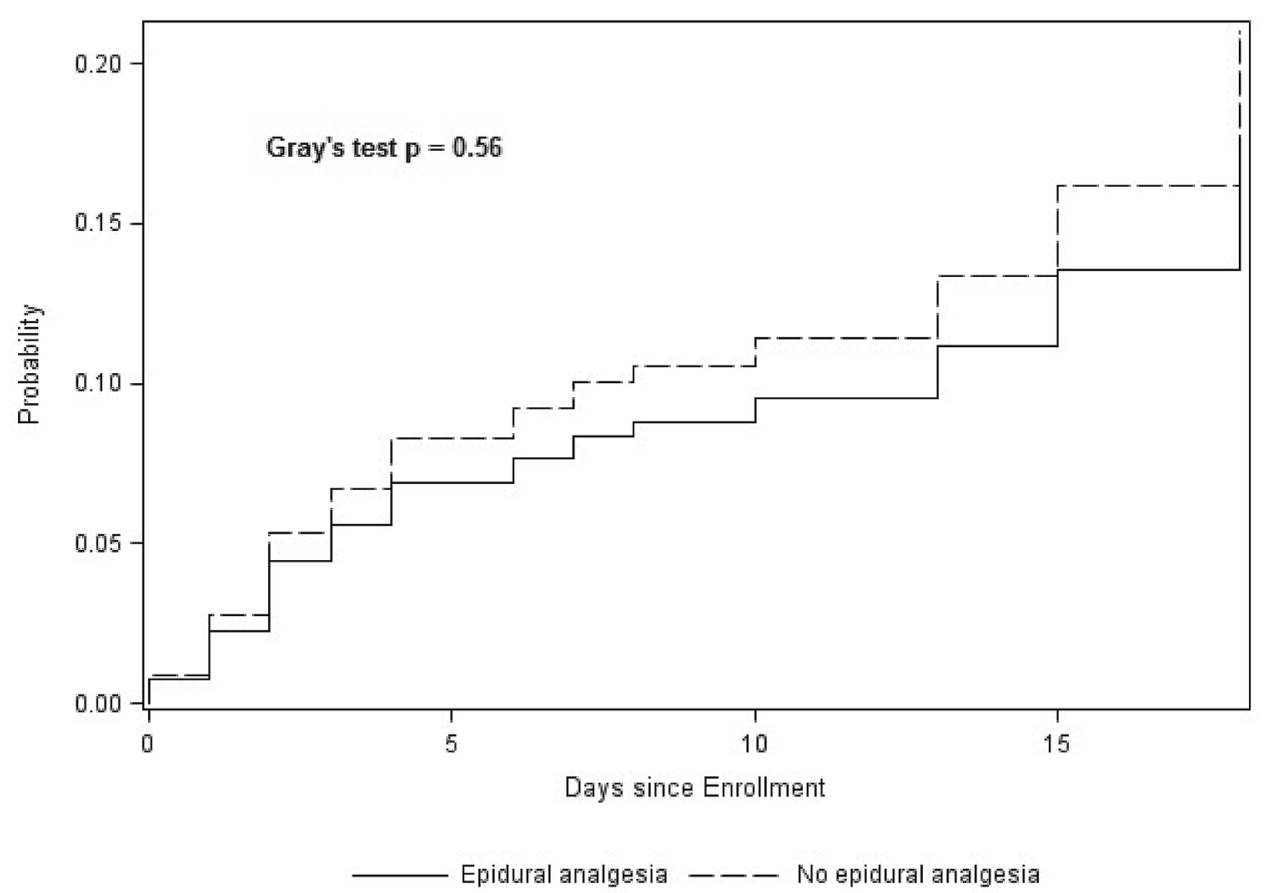

Fig. 1 Cumulative incidence of invasive mechanical ventilation

block and found no difference regarding in-hospital mortality, IMV use or duration, ICU admission, or length of stay. When patients who had either procedure were pooled and compared to patients who had neither procedure, having a procedure was associated with more ICU admissions and longer stays, but having no procedure was associated with greater mortality. In our study of patients with at least three fractured ribs who were not intubated at ICU admission, EA was not associated with decreased IMV requirements.

The associations of EA with worse ISS and thoracic AIS score values and with a larger number of fractured ribs suggest that greater injury severity was a criterion used by physicians to select patients for EA. However, our multivariate analysis excluding patients with contraindications to EA or failure of EA catheter insertion, as well 
as those who refused EA, showed no significant association of EA with a decreased need for IMV. This result was replicated in our sensitivity analysis confined to ICUs where at least 1 study patient received EA. Furthermore, EA was not associated with improved pain control: the groups with and without EA had similar NRS pain scores and intravenous morphine doses over the first 7 ICU days. In three RCTs assessing the efficacy of EA, pain was decreased during coughing and deep breathing, but was not significantly alleviated at rest $[38,41,42]$.

Another possible explanation to the inability of EA to decrease IMV requirements or improve pain control may be failure to identify those patients most likely to benefit from EA. A retrospective study suggested that EA started early after chest trauma was not associated with a lower incidence of pulmonary complications or with shorter ICU or hospital stay lengths [28]. Conceivably, the patients most likely to benefit from EA might be those with risk factors for IMV or ARDS [43, 44]. Pain is a known major risk factor for requiring IMV [45]. Many of our patients had low morphine requirements at the time of EA initiation. Several risk factors for IMV identified in our study have been reported previously, such as variables reflecting the severity of the chest trauma, the presence of an underlying respiratory disease, and the severity of respiratory impairment at ICU admission [12]. An RCT assessing the effects of EA started within $24 \mathrm{~h}$ after the ICU admission of nonintubated chest trauma patients would be expected to provide a sufficiently high level of evidence to allow the development of guidelines.

Our study has several limitations. First, many confounders may have affected our results. The proportion of patients who received EA varied widely across the study ICUs, suggesting marked differences in indications. The indications for starting IMV and the ventilation protocols may also have varied according to local practice. We did not collect several variables of interest such as details on physiotherapy or the occurrence of pain during physiotherapy. Nevertheless, physiotherapy was provided locally according to specific French guidelines for chest trauma patients [17]. Alcohol withdrawal syndrome was a major risk factor for IMV, in keeping with previous data [46]. However, only $4.8 \%$ of patients experienced alcohol withdrawal syndrome and, of the 128 patients who required IMV, only 14 were intubated for neurological reasons. Finally, the number of recruited patients was also extremely variable from one ICU to the next. Second, limitations inherent in the retrospective study design include the existence of missing data and the risk of errors in data abstraction. However, missing data accounted for no more than 5\% of the total. Third, reliable data were unavailable for the use of high-flow nasal oxygen therapy and for several complications. We were thus unable to assess potential associations of EA with deep vein thrombosis and with pulmonary embolism, which were reported in other studies [32]. Several complications of EA such as nausea, vomiting, and mild hypotension were not collected. Finally, patients who received IMV because they required emergent surgery were excluded from the analysis. These patients may have received EA or developed respiratory complications after surgery. A major strength of our study is the large number of patients and participating centers, however our study can be underpowered to detect clinically relevant improvement associated with EA.

\section{Interpretation}

In our large retrospective analysis of 974 patients conducted in 40 ICUs, EA was not associated with decreased IMV needs in chest trauma patients with three or more fractured ribs who were not intubated at ICU admission. EA might, however, have benefits in the subgroup of patients with risk factors for IMV and in patients with severe pain requiring high doses of opioids and/or coanalgesics. RCTs are needed to assess this hypothesis.

\section{Supplementary information}

Supplementary information accompanies this paper at https://doi. org/10.1186/s13613-020-00733-0.

Additional file 1: Figure S1. Patient flow chart

Additional file 2: Figure S2. Proportions of patients given epidural analgesia in each study ICU.

Additional file 3: Table S1. Sensitivity analysis restricted to the 526 patients in ICUs where at least 1 study patient received epidural analgesia.

Additional file 4: Table S2. Sensitivity analysis restricted to the 327 patients with an NRS pain score $>3$ on ICU day 1.

\section{Abbreviations}

95\% Cl: 95\% confidence interval; AIS: Abbreviated Injury Scale; CT: Computed tomography; EA: Epidural analgesia; FRC: Functional residual capacity; ICU: Intensive care unit; ISS: Injury Severity Score; IMV: Invasive mechanical ventilation; NIV: Noninvasive ventilation; NRS: Numerical rating scale; NSAIDs: Nonsteroidal antiinflammatory drugs; RCT: Randomized controlled trial; SAPS II: Simplified Acute Physiology Score version II; VAP: Ventilator-associated pneumonia.

\section{Acknowledgements}

We thank the healthcare staff and research nurses at the trial sites and S. Martin, PharmD, for managing the administrative process and reviewing the manuscript. We thank Dr. A. Wolfe for assistance in preparing and reviewing an earlier version of the manuscript.

\section{Authors' contributions}

$K B, J R$ and JBL conceived and designed the study. $K B, A L, S R, F B, H D, N E, T T, J B$, $B R$, JCC, VB, LF, SG, AJ, PR, JB, CL, MB, LD, ES, MF, AG, MHH, KT, JM, RDV, GP, AH, $M J, T D, S L, R C, F S, F G, B M, A S L, D B$, and $B S$ acquired the study data. $K B, A L T$, JR, $J B L$ performed the statistical analyses and interpreted the results. $K B$, JR, JBL 
drafted the manuscript. KB, JR and JBL interpreted the data and revised the manuscript for important intellectual content. All authors read and approved the final manuscript.

\section{Funding}

Funded by District Hospital Center Vendée, La Roche Sur Yon, France (Year $\left.2015 \mathrm{~N}^{\circ} \mathrm{CHD} 111-16\right)$.

\section{Availability of data and materials}

The dataset is available on reasonable request to the corresponding author.

\section{Ethics approval and consent to participate}

Approval for the retrospective collection of data and data analysis was granted by the ethics committee of the French Intensive Care Society (CE SRLF15-23, 03/07/2015) and by the French Data Protection Authority (CNIL, 12/12/2016).

\section{Consent for publication}

Consent was not required, in accordance with French law on retrospective studies of anonymized data, but patients or relatives were informed of the study protocol and of their right to refuse to participate.

\section{Competing interests}

The authors have no competing interests to declare.

\section{Author details}

${ }^{1}$ Médecine Intensive Réanimation, District Hospital Center, La Roche-sur-Yon, France. ${ }^{2}$ Intensive Care Unit, Regional Hospital Center, Annecy, France. ${ }^{3}$ Plateforme de la méthodologie et de la Biostatistique, Direction de la Recherche Clinique, CHU de Nantes, 44093 Nantes Cedex, France. ${ }^{4}$ Intensive Care Unit, Hospital Center, Angoulême, France. ${ }^{5}$ Intensive Care Unit, Hospital Center, Montauban, France. ${ }^{6}$ Surgical Intensive Care Unit, University Hospital, Amiens, France. ${ }^{7}$ Surgical Intensive Care Unit, University Hospital, Nantes, France. ${ }^{8}$ Intensive Care Unit, Jean Perrin Center, Clermont-Ferrand, France. ${ }^{9}$ Intensive Care Unit, University Hospital, Limoges, France. ${ }^{10}$ University Hospital, Lyon Sud, Lyon, France. ${ }^{11}$ Surgical Intensive Care Unit, Gabriel-Montpied University Hospital, Clermont-Ferrand, France. ${ }^{12}$ Intensive Care Unit, Regional Hospital Center, Roanne, France. ${ }^{13}$ Intensive Care Unit, Regional Hospital Center, Saint-Brieuc, France. ${ }^{14}$ Intensive Care Unit, Regional Hospital Center, Sud Francilien, Corbeil-Essone, France. ${ }^{15}$ Intensive Care Unit, Regional Hospital Center, Dieppe, France. ${ }^{16}$ Surgical Intensive Care Unit, University Hospital, Caen, France. ${ }^{17}$ Intensive Care Unit, Regional Hospital Center, Cherbourg, France. ${ }^{18}$ Intensive Care Unit, Regional Hospital Center, Lorient, France. ${ }^{19}$ Intensive Care Unit, Regional Hospital Center, Puy en Velay, France. ${ }^{20}$ Intensive Care Unit, Regional Hospital Center, Moulins, France. ${ }^{21}$ Intensive Care Unit, Regional Hospital Center, Vichy, France. ${ }^{22}$ Intensive Care Unit, Regional Hospital Center, Périgueux, France. ${ }^{23}$ Intensive Care Unit, Regional Hospital Center, Saint-Malo, France. ${ }^{24}$ Intensive Care Unit, University Hospital, Tenon, Paris, France. ${ }^{25}$ Intensive Care Unit, Regional Hospital Center, Aurillac, France. ${ }^{26}$ Intensive Care Unit, Regional Hospital Center, Orléans, France. ${ }^{27}$ Respiratory Care Unit, University Hospital, Nantes, France. ${ }^{28}$ Intensive Care Unit, Regional Hospital Center, Macon, France. ${ }^{29}$ Intensive Care Unit, Regional Hospital Center, Argenteuil, France. ${ }^{30}$ Intensive Care Unit, Regional Hospital Center, La Rochelle, France. ${ }^{31}$ Department of Perioperative Medicine, CHU Clermont-Ferrand and GReD, CNRS, UMR 6293, INSERM U1103, Universite Clermont Auvergne, Clermont-Ferrand, France. ${ }^{32}$ Medical Intensive Care Unit, University Hospital, Lille, France. ${ }^{33}$ Intensive Care Unit, Regional Hospital Center, Versailles, France. ${ }^{34}$ Neurological Intensive Care Unit, University Hospital, Clermont-Ferrand, France. ${ }^{35}$ Médecine Intensive-Réanimation, Hôpital de Hautepierre, Hôpitaux Universitaires de Strasbourg, Strasbourg, France. ${ }^{36}$ Intensive Care Unit, Regional Hospital Center, Mulhouse, France. ${ }^{37}$ Intensive Care Unit, SaintJoseph Hospital Center, Paris, France. ${ }^{38}$ Intensive Care Unit, Regional Hospital Center, Guéret, France. ${ }^{39}$ Intensive Care Unit, Regional Hospital Center, Châteauroux, France. ${ }^{40}$ Medical Intensive Care Unit, Gabriel-Montpied University Hospital, Clermont-Ferrand, France. ${ }^{41}$ Médecine Intensive Réanimation, University Hospital, Nantes, France.

Received: 27 April 2020 Accepted: 17 August 2020

Published online: 27 August 2020

\section{References}

1. Ziegler DW, Agarwal NN. The morbidity and mortality of rib fractures. J Trauma. 1994;37(6):975-9.

2. Flagel BT, et al. Half-a-dozen ribs: the breakpoint for mortality. Surgery. 2005;138(4):717-23 (discussion 723-725).

3. Bolliger CT, Van Eeden SF. Treatment of multiple rib fractures. Randomized controlled trial comparing ventilatory with nonventilatory management. Chest. 1990;97(4):943-8.

4. Horst $\mathrm{K}$, et al. Thoracic trauma now and then: a 10 year experience from 16,773 severely injured patients. PLoS ONE. 2017;12(10):e0186712.

5. Birkner DR, et al. Mortality of adult respiratory distress syndrome in trauma patients: a systematic review over a period of four decades. World J Surg. 2020;44(7):2243-54.

6. Dehghan $\mathrm{N}$, et al. Flail chest injuries: a review of outcomes and treatment practices from the National Trauma Data Bank. J Trauma Acute Care Surg. 2014;76(2):462-8.

7. Huber $\mathrm{S}$, et al. Predictors of poor outcomes after significant chest trauma in multiply injured patients: a retrospective analysis from the German Trauma Registry (Trauma Register DGU ${ }^{\circledR}$ ). Scand J Trauma Resusc Emerg Med. 2014;22:52.

8. Bulger EM, et al. Rib fractures in the elderly. J Trauma. 2000;48(6):1040-6 (discussion 1046-7)

9. Brasel KJ, et al. Rib fractures: relationship with pneumonia and mortality. Crit Care Med. 2006:34(6):1642-6.

10. Chen J, et al. A chest trauma scoring system to predict outcomes. Surgery. 2014;156(4):988-93.

11. Papazian $\mathrm{L}$, et al. Formal guidelines: management of acute respiratory distress syndrome. Ann Intensive Care. 2019;9(1):69.

12. Battle $C$, et al. Predicting outcomes after blunt chest wall trauma: development and external validation of a new prognostic model. Crit Care. 2014;18(3):R98.

13. Battle $\mathrm{CE}$, Hutchings $\mathrm{H}$, Evans PA. Risk factors that predict mortality in patients with blunt chest wall trauma: a systematic review and metaanalysis. Injury. 2012;43(1):8-17.

14. Simon BJ, et al. Pain management guidelines for blunt thoracic trauma. J Trauma. 2005;59(5):1256-67.

15. Wisner $\mathrm{DH}$. A stepwise logistic regression analysis of factors affecting morbidity and mortality after thoracic trauma: effect of epidural analgesia. J Trauma. 1990;30(7):799-804 (discussion 804-805).

16. Galvagno SM, et al. Pain management for blunt thoracic trauma: a joint practice management guideline from the Eastern Association for the Surgery of Trauma and Trauma Anesthesiology Society. J Trauma Acute Care Surg. 2016;81(5):936-51.

17. Bouzat P, et al. Chest trauma: first 48hours management. Anaesth Crit Care Pain Med. 2017;36(2):135-45.

18. Peek J, et al. Comparison of analgesic interventions for traumatic rib fractures: a systematic review and meta-analysis. Eur J Trauma Emerg Surg. 2019;45(4):597-622.

19. Malekpour M, et al. Analgesic choice in management of rib fractures: paravertebral block or epidural analgesia? Anesth Analg. 2017;124(6):1906-11.

20. Gage A, et al. The effect of epidural placement in patients after blunt thoracic trauma. J Trauma Acute Care Surg. 2014;76(1):39-45 (discussion 45-46).

21. Bulger EM, et al. Epidural analgesia improves outcome after multiple rib fractures. Surgery. 2004;136(2):426-30

22. Spies CD, et al. Intercurrent complications in chronic alcoholic men admitted to the intensive care unit following trauma. Intensive Care Med. 1996;22(4):286-93.

23. Narouze $S$, et al. Interventional spine and pain procedures in patients on antiplatelet and anticoagulant medications (Second Edition): guidelines from the American Society of Regional Anesthesia and Pain Medicine, the European Society of Regional Anaesthesia and Pain Therapy, the American Academy of Pain Medicine, the International Neuromodulation Society, the North American Neuromodulation Society, and the World Institute of Pain. Reg Anesth Pain Med. 2018;43(3):225-62.

24. Rice TW, et al. Comparison of the $\mathrm{SpO}_{2} / \mathrm{FiO}_{2}$ ratio and the $\mathrm{PaO}_{2} / \mathrm{FiO}_{2}$ ratio in patients with acute lung injury or ARDS. Chest. 2007;132(2):410-7.

25. Coudroy R, et al. Reliability of methods to estimate the fraction of inspired oxygen in patients with acute respiratory failure breathing through 
non-rebreather reservoir bag oxygen mask. Thorax. 2020. https://doi. org/10.1136/thoraxjnl-2020-214863.

26. Abbreviated Injury Scale (AIS). Association for the Advancement of Automotive Medicine.

27. Le Gall JR, Lemeshow S, Saulnier F. A new Simplified Acute Physiology Score (SAPS II) based on a European/North American multicenter study. JAMA. 1993;270(24):2957-63.

28. Yeh DD, et al. Epidural analgesia for blunt thoracic injury — which patients benefit most? Injury. 2012;43(10):1667-71.

29. Baker EJ, Lee GA. A retrospective observational study examining the effect of thoracic epidural and patient controlled analgesia on short-term outcomes in blunt thoracic trauma injuries. Medicine. 2016;95(2):e2374.

30. Mayall MF, Calder I. Spinal cord injury following an attempted thoracic epidural. Anaesthesia. 1999;54(10):990-4.

31. Kindler $\mathrm{CH}$, Seeberger MD, Staender SE. Epidural abscess complicating epidural anesthesia and analgesia. An analysis of the literature. Acta Anaesthesiol Scand. 1998;42(6):614-20.

32. Zaw AA, et al. Epidural analgesia after rib fractures. Am Surg. 2015;81(10):950-4.

33. Carrier FM, et al. Effect of epidural analgesia in patients with traumatic rib fractures: a systematic review and meta-analysis of randomized controlled trials. Can J Anaesth. 2009;56(3):230-42.

34. Shelley $\mathrm{CL}$, et al. Posterior paramedian subrhomboidal analgesia versus thoracic epidural analgesia for pain control in patients with multiple rib fractures. J Trauma Acute Care Surg. 2016;81 (3):463-7.

35. Hamilton DL, Manickam B. Erector spinae plane block for pain relief in rib fractures. Br J Anaesth. 2017;118(3):474-5.

36. $\mathrm{Wu} \mathrm{CL}$, et al. Thoracic epidural analgesia versus intravenous patient-controlled analgesia for the treatment of rib fracture pain after motor vehicle crash. J Trauma. 1999:47(3):564-7.

37. Ullman DA, et al. The treatment of patients with multiple rib fractures using continuous thoracic epidural narcotic infusion. Reg Anesth. 1989;14(1):43-7.
38. Mackersie RC, et al. Prospective evaluation of epidural and intravenous administration of fentanyl for pain control and restoration of ventilatory function following multiple rib fractures. J Trauma. 1991;31(4):443-9 (discussion 449-451).

39. Kieninger AN, et al. Epidural versus intravenous pain control in elderly patients with rib fractures. Am J Surg. 2005;189(3):327-30.

40. Duch $\mathrm{P}, \mathrm{M} \varnothing$ ller $\mathrm{MH}$. Epidural analgesia in patients with traumatic rib fractures: a systematic review of randomised controlled trials. Acta Anaesthesiol Scand. 2015;59(6):698-709.

41. Moon MR, et al. Prospective, randomized comparison of epidural versus parenteral opioid analgesia in thoracic trauma. Ann Surg. 1999;229(5):684-91 (discussion 691-692)

42. Luchette FA, et al. Prospective evaluation of epidural versus intrapleural catheters for analgesia in chest wall trauma. J Trauma. 1994;36(6):865-9 (discussion 869-870).

43. Daurat A, et al. Thoracic Trauma Severity score on admission allows to determine the risk of delayed ARDS in trauma patients with pulmonary contusion. Injury. 2016;47(1):147-53.

44. Ramin S, et al. Acute respiratory distress syndrome after chest trauma: epidemiology, specific physiopathology and ventilation strategies. Anaesth Crit Care Pain Med. 2019;38(3):265-76.

45. Easter A. Management of patients with multiple rib fractures. Am J Crit Care. 2001;10(5):320-7 (quiz 328-9).

46. Vartanyan $\mathrm{P}$, et al. Chronic alcoholism is bad for broken ribs: a nationwide analysis of 20,120 patients with rib fractures. J Am Coll Surg. 2019;229(4):S289-90.

\section{Publisher's Note}

Springer Nature remains neutral with regard to jurisdictional claims in published maps and institutional affiliations.

\section{Submit your manuscript to a SpringerOpen ${ }^{\circ}$ journal and benefit from:}

- Convenient online submission

- Rigorous peer review

- Open access: articles freely available online

- High visibility within the field

- Retaining the copyright to your article

Submit your next manuscript at $\boldsymbol{\text { springeropen.com }}$ 